DOI: 10.17058/redes.v20i2.3633

\title{
EMPREGO FORMAL NA AGROPECUÁRIA: UMA ANÁLISE ESPACIAL 1989-2009
}

\author{
FORMAL EMPLOYMENT IN AGRICULTURE: A SPATIAL \\ ANALYSIS 1989-2009
}

\author{
Patrícia Estanislau \\ Universidade Estadual do Paraná - PR - Brasil \\ Paula Tissiany Carneiro \\ Universidade Estadual do Paraná - PR - Brasil \\ Kézia Bondezan \\ Universidade Estadual do Paraná - PR - Brasil \\ José Luiz Parré \\ Universidade Estadual de Maringá - PR - Brasil
}

\begin{abstract}
Resumo: O presente artigo tem por objetivo analisar a distribuição espacial do emprego formal na agropecuária brasileira, total e por gênero, por meio da Análise Exploratória de Dados Espaciais - AEDE. De posse da dispersão do emprego formal entre homens e mulheres, mostra-se se existe interferência do rendimento por gênero deste setor na localização deste emprego formal. O estudo refere-se às 558 microrregiões geográficas do país e foram utilizados os dados da Relação Anual de Informações Sociais - RAIS para os anos de 1989, 1999 e 2009. Identificou-se que, nos três períodos analisados, é evidente a maior participação do Estado de São Paulo em número de contratações formais, tendência esta justificada pela composição de produção agropecuária paulista que possui produtos intensivos em mão de obra, como cana-de-açúcar, café e laranja. Além disso, quando desmembramos o emprego formal por gênero, vem-se observando a elevação no número de contratações de mulheres para trabalhar na agropecuária mantendo este estado como o maior demandante de mão de obra formal para sustentar a expansão das monoculturas. No entanto, esse crescimento acontece em percentual bem menor do que a contratação de mão de obra masculina, ou seja, a participação feminina ainda é tímida no universo do mercado de trabalho formal.
\end{abstract}

Palavras-chave: Emprego formal na agropecuária. Gênero. Efeitos espaciais. 
Abstract: This article aims to analyze the spatial distribution -total and by gender - of formal employment in Brazilian agriculture, by exploratory spatial data analysis (ESDA). After collecting data and analyzing the dispersion of formal employment for men and women, it is possible to show whether there is interference from the income of this sector by gender in the location of formal employment, that refers to the 558 geographical micro-regions of the country and the Annual Relation of Social Information (RAIS) was used for the years 1989, 1999 and 2009. Clear participation of the largest state of Sao Paulo in the number of formal contracts was identified on the three study periods. This trend was explained by the composition of agricultural production of the state which has products that require intensive labor, such as sugar cane, coffee and orange. Furthermore, it has been observed, when unbundled formal employment by gender, an increase in the number of hiring women to work in agriculture. This fact maintains this state as the largest applicant's formal workforce to support the expansion of plantations. However, this growth occurs in a percentage much lower than hiring manpower male, so, female participation is still limited in the universe of formal labor market.

Key Words : Employment in agriculture. Gender. Spatial effects.

\section{INTRODUÇÃO}

As mudanças estruturais ocorridas na economia brasileira, a partir da década de 1990, com a abertura comercial e o aumento da competitividade, repercutiram sobre o espaço rural, intensificando a modernização agrícola e inserindo novas atividades no seu interior, gerando a ideia de pluriatividade. Essas transformações captam não só o incremento tecnológico e produtivo, mas a emergência de um novo conceito de ruralidade, que pode ser resumido em uma agropecuária moderna e intensiva em commodities, na urbanização do campo e num conjunto de atividades não agrícolas.

Nesse ambiente de mudanças, o mercado de trabalho rural vem sendo ocupado por atividades com moldes tecnificados - poupadores de mão de obra -, e por práticas modernas de produção. Aliado a isso, a literatura destaca alguns fatores específicos da agropecuária brasileira e que definem este mercado, dos quais se pode elencar: a terceirização ou externalização de atividades agrícolas para empresas prestadoras de serviços (GRAZIANO DA SILVA, 1996), a maior fiscalização por parte do estado quanto aos direitos sociais, trabalhistas e ambientais, o que elevou o número de registros em carteira (LEONE et al, 2007) e a maior demanda pelos trabalhadores temporários nas atividades agropecuárias 
(HOFFMANN, 2009). Segundo este autor, a remuneração média dos empregados permanentes é cerca de $70 \%$ acima da remuneração dos empregados temporários. No entanto, essa desigualdade não se verifica na proporção dos empregados com registro em carteira, que é um indicador básico da formalização dos vínculos empregatícios, que mostra clara tendência crescente, tanto entre empregados permanentes como entre empregados temporários.

Com esse quadro de referência, o mercado agrícola brasileiro passou por profundas transformações que permeiam as ocupações, a geração de renda e a melhoria das relações de trabalho. Nesse contexto, este estudo tem como objetivo mapear a dispersão do emprego formal na agropecuária' brasileira, total e por gênero, a partir da análise de dados da RAIS para os anos de 1989, 1999 e 2009. Ou seja, analisar a evolução do emprego formal no meio rural, onde as atividades agrícolas têm forte representação, e como esta formalização foi distribuída entre homens e mulheres ocupados. De posse dessa distribuição, mostrar-seá se existe interferência do rendimento na agropecuária sobre a localização desse emprego formal.

Para cumprir o objetivo proposto, a metodologia adotada será a $A E D E$, que permite alocar esforços para testar a hipótese de que houve aumento do emprego formal total e por gênero, mas que a demanda por mão de obra feminina, embora crescente, ainda é inferior à alocação de mão obra masculina na agropecuária.

Além desta breve introdução, este artigo está segmentado em mais três seções. A segunda seção examina, preambularmente, as transformações ocorridas na agropecuária brasileira a partir da década de 1990 e o seu impacto sobre o mercado de trabalho rural, constituída pela revisão de literatura. A terceira seção aborda em síntese a metodologia do estudo exploratório e, após, segue-se a quarta seção correspondente aos resultados e discussões. Por fim, sumarizando este trabalho, são tecidas algumas considerações finais.

\section{REVISÃO DE LITERATURA}

\footnotetext{
Pela classificação da RAIS, o setor agropecuário compreende: Agricultura, pecuária e serviços relacionados; Silvicultura, exploração florestal e serviços relacionados; Pesca e aquicultura e serviços relacionados.
} 
A questão do nível de emprego e desemprego tem sido pauta de discussões importantes no meio acadêmico, político e de comunicação em geral, sendo uma das principais variáveis do mercado de trabalho. Essa discussão ganha propriedade a partir de 1990, quando se observou uma queda acentuada no nível de emprego formal, justificada, principalmente, pelas mudanças na forma de utilização do trabalho, na terceirização dos serviços, bem como na elevação da produtividade que adveio da modificação da estrutura produtiva.

Quando essa discussão é levada para o mercado de trabalho no meio rural, os resultados não são diferentes. Para Staduto et al (2004), as mudanças nos ambientes institucional e econômico, a partir de 1985, e com mais evidência nos anos de 1990, levaram a uma nova fase de inovação tecnológica, principalmente, no processo de mecanização, o que afetou as principais culturas de produção brasileira, como cana-deaçúcar, algodão e café e que resultaram numa redução considerável na demanda por trabalhadores agrícolas.

Nessa direção, vários autores ressaltam que as ocupações do setor agrícola se sofisticaram com a adoção de tecnologias poupadoras de mão de obra braçal e demandantes de mais mão de obra qualificada. Dentre esses estudos, cabe destacar os trabalhos de Graziano da Silva (1996), Gasques e Conceição (1997), Kageyama (2004), Staduto et al (2004), Del Grossi e Graziano da Silva (2006). O enfoque principal desses trabalhos consiste em mostrar que todo esse aporte tecnológico aumentou a produtividade do trabalho e da terra e mudou tanto a organização da produção quanto as relações de trabalho.

Para Casari (2012), a tecnologia tem uma relação endógena com a qualificação, pois demanda um nível educacional tanto do produtor que adota a tecnologia, quanto de trabalhadores (qualificados e permanentes), o que gera um grande impacto sobre o mercado de trabalho desse setor. No entanto, Freitas, Bacha e Fossatti (2007) apontam que o nível de tecnificação do setor agropecuário no Brasil ainda é bastante desigual entre as regiões. Para os autores, o desenvolvimento da agropecuária nos estados está intimamente relacionado à qualificação dos seus trabalhadores e empresários. Esta variável esta que ainda é um obstáculo, visto que a escolaridade no meio rural ainda é baixa e desigual entre as regiões. 
Nesse contexto de modernização, Staduto, Shikida e Bacha (2004) mostram o impacto da trajetória tecnológica do setor agropecuário sobre o tipo de mão de obra assalariada utilizada. No período de 1970 a 1985, houve um aumento da participação da mão de obra temporária no total de mão de obra assalariada empregada na agropecuária brasileira. Nesse período, algumas fases do processo produtivo não eram mecanizadas e demandavam esses trabalhadores para executar as tarefas. A partir de 1985, acontece um movimento contrário, reduzindo a sazonalidade e o uso de trabalhadores temporários, substituindo-os por mão de obra permanente e qualificada, aptas a participar do novo ciclo de inovações tecnológicas. Essa mudança na composição do trabalho assalariado é seguida pelo aumento da especialização dos trabalhadores agrícolas, principalmente dos postos permanentes.

Outro aspecto importante no mercado de trabalho assalariado da agropecuária brasileira é a polarização na qualidade do emprego, que pode ser medida pelo rendimento médio mensal recebido no trabalho principal. Segundo Balsadi (2007), as culturas mais tradicionais e de mercado interno, como milho, arroz e mandioca, apresentam os piores rendimentos para os trabalhadores temporários ocupados com estas culturas. Por outro lado, os melhores rendimentos estavam nas culturas de soja e cana-de-açúcar que representam duas das principais commodities internacionais. Os melhores rendimentos acontecem entre os empregados permanentes urbanos e rurais ocupados na cultura de soja e os empregados permanentes urbanos ocupados na cultura de cana-de-açúcar, evidenciando os fortes contrastes ainda existentes no mercado de trabalho assalariado agrícola.

Além da rentabilidade média do trabalhador, Balsadi (2007) aponta outros fatores que explicam o fenômeno da polarização da qualidade do emprego agrícola no Brasil: a crescente especialização, modernização e mecanização da produção de commodities internacionais visando obter maiores produtividades; a terceirização das atividades ligadas à agricultura; a maior fiscalização nas empresas agrícolas de maior porte, para garantir a legislação trabalhista; a crescente busca por certificações nas atividades mais sustentáveis; a criação de algumas novas profissões; a utilização, em larga escala, da mão de obra temporária nas atividades agropecuárias; e a fraca representação e organização sindical dos trabalhadores temporários. 
Ainda explorando a variável rendimento médio mensal dos assalariados, Cunha (2008) analisou os diferenciais e os determinantes salariais dos empregados da agricultura brasileira, no período de 1981 a 2005. Para a autora, a desigualdade salarial no setor agrícola vem reduzindo significativamente a partir de 1990, seguindo a tendência observada no mercado de trabalho brasileiro. A variável educação reduziu o diferencial de salários para o período analisado (qualificados e não qualificados), mas, ainda, há um longo caminho a percorrer, visto que a escolaridade média no setor agrícola é tradicionalmente mais baixa que a média brasileira. Quanto ao impacto do salário mínimo sobre os rendimentos no setor agrícola, o estudo aponta uma relação positiva, ou seja, grande parte do rendimento agrícola é determinada pelo salário mínimo nacional. No entanto, a modernização agrícola, que gerou aumentos da produtividade do trabalho, não está sendo traduzida em aumentos dos salários reais do setor.

Por fim, Leone et al (2007) e Schneider (2006) apontam a atuação mais severa que os órgãos de fiscalização do trabalho passaram a ter em relação às condições de trabalho no meio rural, como a maior exigência de contratualização do trabalho temporário e a maior coerção às formas de trabalho análogas à servidão que passou a ser vigiado por um órgão especializado. Houve, também, um maior acesso à informação pelo produtor rural a respeito de seus direitos e de suas obrigações legais e a promulgação da Emenda Constitucional $n^{\circ} 28$, de 25 de maio de 2000, que equiparou em cinco anos o prazo de prescrição dos direitos trabalhistas no campo e na cidade. Essas medidas parecem ter ajudado na melhoria da formalização das relações de trabalho no meio rural e podem ter contribuído para a sua elevação.

Em se tratando do gênero no mercado de trabalho, estudos apontam que a força de trabalho feminino vem aumentando ao longo dos anos. Em 1993, a População Economicamente Ativa - PEA feminina correspondia a $39,6 \%$ do total, já no ano de 2005 saltou para $43 \%$. A taxa de ocupação que era de $39 \%$ em 1993 , saltou para $42,1 \%$ no ano de 2005. Esses resultados corroboram com as transformações demográficas e sociais ocorridas nas últimas décadas, tais como: queda na taxa de fecundidade, redução do tamanho das famílias, aumento da expectativa de vida ao nascer e novos arranjos familiares chefiados por mulheres. Além disso, mudanças nos padrões culturais também 
permitiram uma nova dinâmica no mercado de trabalho, como exemplo, cita-se: o novo papel social da mulher, em que o trabalho remunerado é cada vez mais acentuado no universo feminino, e o acesso ao ensino superior, que gera novas oportunidades de trabalho (BRUSCHINI, 2007)

No que tange ao mercado de trabalho rural, é possível observar, também, que a agricultura é uma atividade extensiva em mão de obra feminina. Microdados da Pesquisa Nacional por Amostra de Domicílios PNAD (2005) apontam que os setores que mais empregaram mulheres foram: Serviços domésticos (16,93\%); Educação, saúde e serviços sociais $(16,14 \%)$ e Agricultura (16,02\%). Essas estatísticas demonstram a importância do setor agrícola para o mercado de trabalho feminino.

\section{METODOLOGIA}

O presente trabalho adota como metodologia o uso de técnicas de distribuição espacial por meio da AEDE. O objetivo é visualizar melhor o comportamento das variáveis e determinar onde ocorrem tais variações, ou seja, a localização geográfica das variáveis em questão.

\subsection{Análise Exploratória de Dados Espaciais}

Segundo Perobelli et al (2005), a AEDE considera os aspectos espaciais contidos nas variáveis, por conseguinte, os efeitos decorrentes da dependência espacial e da heterogeneidade espacial. Ou seja, é uma coleção de técnicas de análise estatística de informação geográfica para expor distribuições espaciais, encontrar padrões de associação espacial ou cluster, verificar a presença de diferentes regimes espaciais ou outras formas de instabilidade (não estacionariedade) e identificar outliers.

Por definição, tem-se:

a AEDE é tida como pré-requisito ao estudo da econometria espacial, subcampo da econometria que lida com as complicações causadas pela interação espacial (autocorrelação espacial) e pela estrutura espacial (heterogeneidade espacial) em modelos de regressão para dados na forma de cross-section e painel de dados. 
Sendo assim, mostra-se importante na identificação de observações discrepantes no espaço e possíveis padrões de associação espacial. (ROCHA e PARRÉ, 2009, p. 143)

Esses autores colocam que, a partir daí, é possível extrair medidas de autocorrelação espacial global e local, investigando a influência dos efeitos espaciais por meio de métodos quantitativos.

\subsubsection{Autocorrelação Espacial Global}

O primeiro passo a ser realizado na AEDE é testar a distribuição espacial dos dados. Conforme Almeida (2004), há um conjunto de estatísticas que investigam a presença da autocorrelação espacial2. Para verificar se existe a autocorrelação espacial, primeiramente utiliza-se o coeficiente de correlação espacial Global I de Moran Univariado3:

$$
I=\frac{n}{\sum \sum W \underline{i j}} \frac{\sum \sum w i j\left(y_{i}-\bar{y}\right)\left(y_{j}-\bar{y}\right)}{\sum w i j\left(y_{i}-\bar{y}\right)^{2}}
$$

Em que $n$ é o número de unidades espaciais, $y_{i}$ é a variável de interesse, $w_{i j}$ é o peso espacial para o par de unidades espaciais $i$ e $j$, medindo o grau de interação entre elas. A indicação de autocorrelação espacial positiva indica que há similaridade entre os valores dos atributos estudados e a localização do mesmo, para isso compara-se com o valor esperado de I de Moran $E(I)=-1 /(n-1)$ em que os valores de I Esperado são maiores (ou menores), o que significa que há autocorrelação positiva (ou negativa).

Para possibilitar o cálculo do coeficiente I de Moran, faz-se necessário escolher uma matriz de peso, que define o grau de proximidade entre as microrregiões. Portanto, ela está associada à distância entre as regiões ou aos limites geográficos (fronteiras) existentes (ALMEIDA, 2004). Para o presente trabalho, adota-se a

2 Se existe a coincidência da similaridade de valores de uma variável com a similaridade da localização dessa variável.

3 Conforme este autor, a autocorrelação espacial global pode ser averiguada num contexto multivariado. A ideia intuitiva é descobrir se os valores de uma variável observada numa dada região guarda uma relação sistemática com os valores de uma outra variável observada em regiões vizinhas. 
estrutura de pesos espaciais binários na convenção de rainha, com vizinhos de primeira ordem.

No entanto, é importante ressaltar que a estatística I de Moran é uma medida global, o que não torna possível a estrutura de correlação espacial regional.

\subsubsection{Autocorrelação Espacial Local}

De acordo com Pinheiro (2007), a estatística I de Moran é uma medida global, portanto, não é possível observar a estrutura de correlação espacial em nível local. Isso porque, a indicação de padrões globais de associação espacial pode estar em conformidade com padrões locais, embora não seja necessariamente o caso que prevalece. Neste caso, Perobelli et al (2005) identifica três situações distintas. A primeira envolve a indicação de um I de Moran global insignificante, podendo ocorrer indicações de autocorrelação espacial insignificante. A segunda implica um I de Moran global, que oculta autocorrelação espacial local negativa e insignificante. A terceira indica que a evidência de uma autocorrelação espacial global negativa pode acomodar indícios de autocorrelação espacial local positiva para certos grupos de dados. Daí reside a importância de se avaliar o padrão local de autocorrelação espacial.

Para identificar a ocorrência de autocorrelação local, segundo Almeida (2004), Luc Anselin propôs, em 1995, uma decomposição em categorias do indicador I de Moran, dado por:

$$
I_{i}=\frac{\left(y_{i}-\bar{y}\right) \sum_{j} w i j\left(y_{j}-\bar{y}\right)}{\sum_{i}\left(y_{i}-\bar{y}\right)^{2} / n}=z_{i} \sum_{j} w_{i j} z_{j}
$$

em que $y_{i}$ e $y_{j}$ são variáveis padronizadas e a somatória sobre j é tal que somente os valores dos vizinhos $j \epsilon_{\mathrm{J}_{\mathrm{i}}}$ são incluídos. O conjunto $\mathrm{J}_{\mathrm{i}}$ abrange os vizinhos da observação $i$.

Sob o pressuposto da aleatorizaçao, o valor esperado da estatística / de Moran local é dado por: $\mathrm{E}(\mathrm{li})=-$ wi $/(\mathrm{n}-1)$, em que wi é o somatório dos elementos da linha. 


\subsubsection{Diagramas de dispersão de Moran}

Conforme descrito por Perobelli et al (2005), o diagrama de dispersão de Moran é uma das formas de interpretar a estatística / de Moran. Em outras palavras, permite visualizar a correlação linear entre $z$ e $W z$ através do gráfico de duas variáveis. No caso específico da estatística / de Moran, tem-se o gráfico de $W z$ e $z$, conforme Figura 1. Portanto, o coeficiente / de Moran será a inclinação da curva de regressão de $W z$ contra $z$ e esta inclinação indicará o grau de ajustamento.

Figura 1. Diagrama de dispersão de Moran

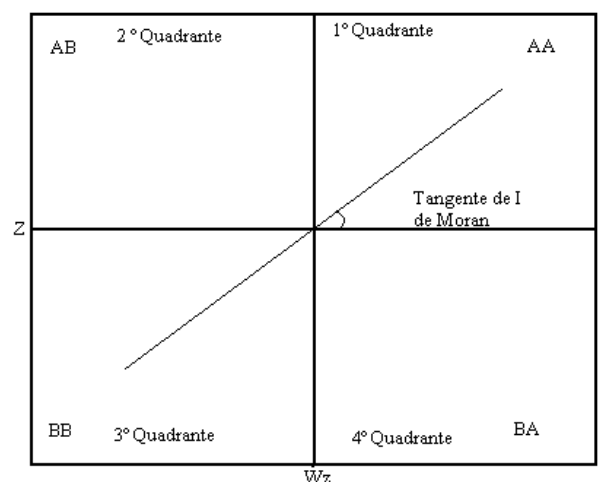

Fonte: Compilação de Almeida (2004)

De acordo com Almeida (2004), esse digrama está dividido em quatro tipos de associação espacial que correspondem a quatro padrões de associação local espacial entre as regiões e seus vizinhos.

O primeiro quadrante (AA), localizado na parte superior direita, é a região com valores acima da média para o atributo em análise cercado por vizinhos com valores também acima da média para a mesma variável. O segundo quadrante (BA), localizado na parte superior esquerda, mostra o agrupamento na região com o atributo com valores abaixo da média, cercado por vizinhos com valores da mesma variável acima da média. O terceiro quadrante (BB), localizado na parte inferior esquerda, aponta a região com o atributo com valores abaixo da média, cercado por vizinhos com valores da mesma variável abaixo da média. 
Por fim, o quarto quadrante (AB), localizado na parte inferior direita, região com o atributo com valores acima da média, cercado por vizinhos com valores da mesma variável abaixo da média.

As regiões que estão localizadas nos quadrantes $A A$ e $B B$ apresentam autocorrelação espacial positiva, ou seja, formam clusters de valores similares. Por outro lado, os quadrantes $B A$ e $A B$ apresentam autocorrelação espacial negativa, formando clusters com valores diferentes.

\subsection{Descrição das Variáveis e Fonte de Dados}

Os dados utilizados neste trabalho referem-se à RAIS referentes aos anos de 1989, 1999 e 2009, segmentados nas 558 microrregiões brasileiras. 
Quadro 2. Descrição das Variáveis Utilizadas

\begin{tabular}{|l|l|}
\hline \multicolumn{1}{|c|}{ VARIAVEIS } & \multicolumn{1}{c|}{ DESCRIÇÃO } \\
\hline MASC89 & Emprego formal na agropecuária do sexo masculino no ano de 1989 \\
\hline FEM89 & Emprego formal na agropecuária do sexo feminino no ano de 1989 \\
\hline T89 & Emprego formal na agropecuária total no ano de 1989 \\
\hline MASC99 & Emprego formal na agropecuária do sexo masculino no ano de 1999 \\
\hline FEM99 & Emprego formal na agropecuária do sexo feminino no ano de 1999 \\
\hline T99 & Emprego formal na agropecuária total no ano de 1999 \\
\hline MASC09 & Emprego formal na agropecuária do sexo masculino no ano de 2009 \\
\hline FEM09 & Emprego formal na agropecuária do sexo feminino no ano de 2009 \\
\hline T09 & Emprego formal na agropecuária total no ano de 2009 \\
\hline RENM89 & $\begin{array}{l}\text { Média do rendimento em salários mínimos do sexo masculino para } \\
\text { agropecuária em } 1989\end{array}$ \\
\hline RENF89 & $\begin{array}{l}\text { Média do rendimento em salários mínimos do sexo feminino para } \\
\text { agropecuária em 1989 }\end{array}$ \\
\hline RENM99 & $\begin{array}{l}\text { Média do rendimento em salários mínimos do sexo masculino para } \\
\text { agropecuária em 1999 }\end{array}$ \\
\hline RENF99 & $\begin{array}{l}\text { Média do rendimento em salários mínimos do sexo feminino para } \\
\text { agropecuária em } 1999\end{array}$ \\
\hline RENM09 & $\begin{array}{l}\text { Média do rendimento em salários mínimos do sexo masculino para } \\
\text { agropecuária em 2009 }\end{array}$ \\
\hline RENF09 & $\begin{array}{l}\text { Média do rendimento em salários mínimos do sexo feminino para } \\
\text { agropecuária em 2009 }\end{array}$ \\
\hline
\end{tabular}

Fonte: Elaboração própria a partir da RAIS.

\section{RESULTADOS E DISCUSSÕES}

Segundo Del Grossi \& Graziano da Silva (2006), nas últimas décadas, tem-se observado, no Brasil, a emergência de uma nova ruralidade expressada, principalmente, pelo crescimento de populações com residência rural e ocupados em atividades não agrícolas e pelo progresso técnico na produção agropecuária, que tem continuado e levado a uma simplificação de suas tarefas.

$\mathrm{Na}$ direção dessas mudanças no meio rural, Leone et al (2007) apontam o aumento da formalização dos contratos, que responde por uma parcela significativa do emprego formal, de, aproximadamente, $40 \%$ das contratações. Como citado anteriormente, isto se deve ao maior acesso à informação por parte do produtor rural sobre seus direitos e obrigações legais, à fiscalização das leis trabalhistas e à promulgação da 
Emenda Constitucional $n^{\circ} 28$, de 25 de maio de 2000, que equiparou em cinco anos o prazo de prescrição dos direitos trabalhistas no campo e na cidade. A seguir, a Figura 2 mostra essa evolução do total de empregos formais na agropecuária. Percebe-se visualmente que houve uma expansão da área de emprego formal nos períodos de 1989, 1999 e 2009.

Figura 2. Mapas do Total de Empregos Formais na Agropecuária em 1989, 1999 e 2009

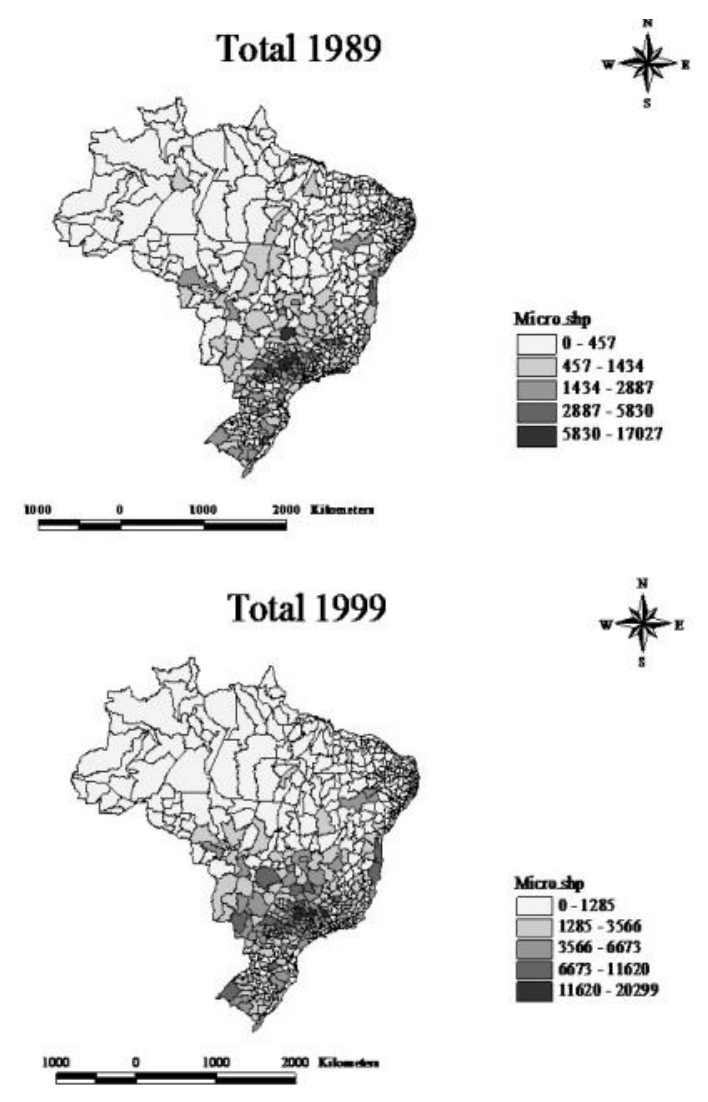




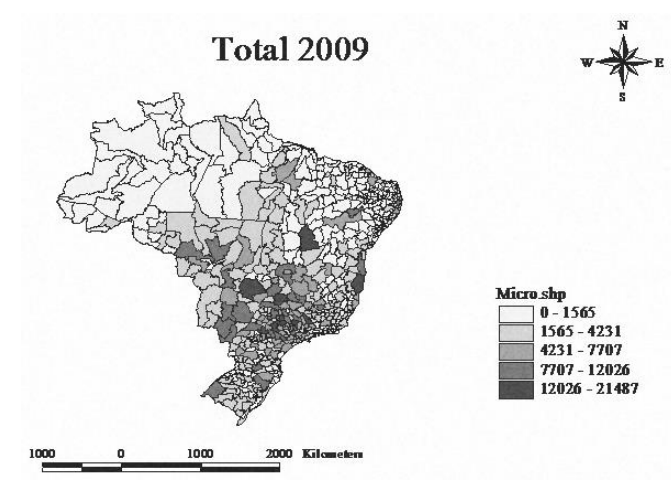

Fonte: Elaboração própria a partir dos dados da RAIS.

Em 1989, do total de empregos formais no Brasil (77.611), o interior do Estado de São Paulo concentrava 52.715, o que garantia um percentual de $68 \%$ das contratações. No ano 1999, com a mesma localização, totalizava-se 88.522 empregos formais agrícolas, frente a um total nacional de 142.256. Já no ano de 2009, houve uma pequena redução no emprego formal da região de São Paulo, registrando 86.707, e um espraiamento para os estados de Minas Gerais, Bahia e Goiás, totalizando 157.399 empregos formais na agropecuária brasileira. 
Quadro 1. Ranking das dez maiores microrregiões brasileiras geradoras de emprego formal na agropecuária para os anos de 1989, 1999 e 2009

\begin{tabular}{|c|c|c|c|c|c|c|c|c|c|c|c|}
\hline \multicolumn{4}{|c|}{1989} & \multicolumn{4}{|c|}{1999} & \multicolumn{4}{|c|}{2009} \\
\hline Microrregiões & $\begin{array}{l}\text { Empregos } \\
\text { (A) }\end{array}$ & $\begin{array}{l}\text { Firmas } \\
\text { Rurais } \\
\text { (B) }\end{array}$ & $A / B$ & Microrregiões & $\begin{array}{l}\text { Empregos } \\
\text { (A) }\end{array}$ & $\begin{array}{l}\text { Firmas } \\
\text { Rurais } \\
\text { (B) }\end{array}$ & $A / B$ & Microrregiões & $\begin{array}{l}\text { Empregos } \\
\text { (A) }\end{array}$ & $\begin{array}{l}\text { Firmas } \\
\text { Rurais } \\
\text { (B) }\end{array}$ & $A / B$ \\
\hline $\begin{array}{l}\text { Ribeirão Preto } \\
\text { SP }\end{array}$ & 17.027 & 175 & 97,86 & $\begin{array}{l}\text { Ribeirão Preto } \\
\text { SP }\end{array}$ & 20.299 & 1.471 & 13,80 & Araraquara SP & 21.487 & 1.418 & 15,15 \\
\hline Araraquara SP & 9.023 & 230 & 39,23 & Varginha MG & 17.364 & 3.677 & 4,72 & Jaboticabal SP & 19.988 & 1.896 & 7.88 \\
\hline Jaú SP & 8.529 & 84 & 101,54 & Araraquara SP & 16.911 & 2.097 & 8,06 & Assis SP & 16.060 & 1.229 & 13,07 \\
\hline $\begin{array}{l}\text { Rio de Janeiro } \\
\text { RJ }\end{array}$ & 6.698 & 1.565 & 4,28 & Jaboticabal SP & 16.744 & 1.886 & 8,84 & $\begin{array}{l}\text { Sudoeste de } \\
\text { Goiás GO }\end{array}$ & 15.833 & 699 & 22,65 \\
\hline Assis SP & 6.535 & 93 & 70,27 & $\begin{array}{l}\text { São João da Boa } \\
\text { Vista SP }\end{array}$ & 13.887 & 2.440 & 5,69 & $\begin{array}{l}\text { São João da } \\
\text { Boa Vista SP }\end{array}$ & 15.369 & 1221 & 10,05 \\
\hline Bauru SP & 6.440 & 206 & 31,26 & $\begin{array}{l}\text { São Sebastião } \\
\text { do Paraíso MG }\end{array}$ & 13.281 & 1.991 & 6,67 & Varginha MG & 14.320 & 1949 & 7,35 \\
\hline Uberlândia & 6.204 & 346 & 17,93 & Uberlândia MG & 11.620 & 2.91990 & 3,89 & Bauru SP & 13.803 & 3468 & 3,98 \\
\hline
\end{tabular}


Patrícia Estanislau, Paula Tissiany Carneiro, Kézia Bondezan, José Luiz Parré

\begin{tabular}{|c|c|c|c|c|c|c|c|c|c|c|c|}
\hline \multicolumn{12}{|l|}{ MG } \\
\hline São Paulo SP & 5.830 & 1.248 & 4,67 & Jaú SP & 10.389 & 1.096 & 9,48 & Uberlândia MG & 13.462 & 705 & 19,10 \\
\hline Campinas SP & 5.161 & 278 & 18,56 & $\begin{array}{l}\text { São José do Rio } \\
\text { Preto SP }\end{array}$ & 10.292 & 3.048 & 3,38 & Barreiras BA & 13.278 & 1.469 & 9,04 \\
\hline
\end{tabular}

Fonte: Resultados da Pesquisa. 
Nota-se, conforme Quadro 1, que a razão empregos agropecuários e estabelecimentos agropecuários diminuiu entre os anos de 1989 e 2009. Em parte, isso se deve à elevação do número de estabelecimentos rurais ao longo do período. O que, por hora, significa talvez a redução de grandes propriedades em razão do aumento de propriedades rurais menores.

É importante ressaltar que, nos três períodos analisados, é evidente a maior participação do Estado de São Paulo em número de contratações que respondem por $68 \%$ em 1989, 62\% em 1999 e 55\% em 2009. Para Vicente (2005), essa tendência é justificada pela composição de produção agropecuária paulista que possui produtos intensivos em mão de obra, como cana-de-açúcar, café e laranja. Dessa forma, apresentam elevada contribuição na dinâmica de ocupação da mão de obra rural, apesar da diversidade de atividades da sua pauta de produção.

Todavia, apesar do mapa apresentar informações importantes ao destacar as áreas com maior número de empregos formais da agropecuária, a mera visualização pode levar ao erro. Por este motivo, torna-se necessário realizar testes de aleatoriedade para verificar toda a tendência dos dados em análise. Para este caso, foi aplicado o diagrama de dispersão de Moran (I de Moran), que indica o grau de dependência espacial. Os valores acima do I de Moran calculado representam a existência da autocorrelação espacial positiva e os valores abaixo representam a autocorrelação espacial negativa.

Dessa forma, como mostrado na Tabela 1, o indicador I de Moran univariado sinaliza que há autocorrelação espacial global, pois o seu coeficiente é $(0,3292),(0,4868)$ e $(0,4668)$ para o emprego formal na agropecuária nos anos de 1989, 1999 e 2009, respectivamente. Considerando que E (I) é $-0,0018$, existe autocorrelação positiva entre as regiões. Este coeficiente é significativo, pois o seu P-valor é 0,01 para 999 permutações randômicas. Ou seja, as microrregiões com maior número de emprego formal são circunvizinhas de microrregiões com elevado numero de emprego formal.

Tabela 1. Coeficiente de I de Moran do Emprego formal total na agropecuária para os anos de 1989, 1999 e 2009 


\begin{tabular}{lll}
\hline Variáveis & $\mathbf{I}$ & Probabilidade \\
\hline T89 & 0,3292 & 0,01 \\
T99 & 0,4868 & 0,01 \\
T09 & 0,4668 & 0,01 \\
\hline
\end{tabular}

Fonte: Resultados da pesquisa.

Nota: a pseudo-significância empírica é baseada em 999 permutações aleatórias.

A seguir, são apresentados os indicadores da evolução da ocupação de trabalhadores por gênero, descrevendo, assim, o perfil do emprego formal da agropecuária no Brasil.

\subsection{0 emprego formal na agropecuária por gênero}

Quando se desmembra o emprego formal por gênero, verifica-se uma pequena modificação na distribuição entre as microrregiões brasileiras. Na tabela 3, tem-se o total de vínculos formais por microrregiões por gênero e o que se observa é a elevação no número de contratações de mulheres para trabalhar na agropecuária. Vicente (1998) justifica essa evolução afirmando que a modernização da agricultura, ao vir acompanhada da monocultura crescente, trouxe uma importante intensificação da ocupação das trabalhadoras para sustentar sua expansão. Dessa forma, integrou-se a mulher no mercado de trabalho assalariado.

Verifica-se que, no ano 1989, a microrregião de Ribeirão Preto (SP) foi responsável pelo maior número de empregos formais masculinos e femininos. O mesmo fato pode ser visto, também no ano de 2009 com a microrregião de Araraquara (SP). Nota-se que a razão entre empregos e estabelecimentos agropecuários é maior para o gênero masculino, devido à maior proporção de empregos.

Ao analisar a evolução dos três períodos, confirma-se o aumento do emprego formal feminino que, com o assalariamento, vai deixando de ser caracterizado como complemento do emprego masculino. Isso pode ser verificado quando se compara as estimativas do final da década de 1980 com o ano de 2009. Passados 20 anos, o aumento do 
numero de mulheres assalariadas com carteira assinada aconteceu não só no Estado de São Paulo como também em regiões que antes não apresentavam números significativos de contratações, como Joaçaba (SC), Vacaria (RS) e Sudoeste de Goiás (GO), o que representou um aumento de $70 \%$. A despeito de São Paulo, é pertinente observar que esse estado ainda concentra a maioria desta demanda formal de mão de obra feminina. 
Quadro 2. Ranking das dez maiores microrregiões brasileiras geradoras de emprego formal na agropecuária para os anos de 1989, 1999 e 2009 por gênero

\begin{tabular}{|c|c|c|c|c|c|c|c|c|c|c|c|}
\hline \multicolumn{12}{|c|}{ MASCULINO } \\
\hline \multicolumn{4}{|c|}{1989} & \multicolumn{4}{|c|}{1999} & \multicolumn{4}{|c|}{2009} \\
\hline Microrregiões & $\begin{array}{l}\text { Empreg } \\
\text { os (A) }\end{array}$ & $\begin{array}{c}\text { Firmas } \\
\text { Rurais } \\
\text { (B) }\end{array}$ & $A / B$ & Microrregiões & $\begin{array}{l}\text { Empreg } \\
\text { os (A) }\end{array}$ & $\begin{array}{c}\text { Firmas } \\
\text { Rurais } \\
\text { (B) }\end{array}$ & A/B & Microrregiões & $\begin{array}{l}\text { Empreg } \\
\text { os (A) }\end{array}$ & $\begin{array}{c}\text { Firma } \\
\text { s } \\
\text { Rurais } \\
\text { (B) }\end{array}$ & A/B \\
\hline Ribeirão Preto SP & 14.502 & 175 & $\begin{array}{r}82,8 \\
7 \\
\end{array}$ & Ribeirão Preto SP & $\begin{array}{r}17.1990 \\
3 \\
\end{array}$ & 1.471 & $\begin{array}{r}12,1 \\
7 \\
\end{array}$ & Araraquara SP & 15.617 & 1.418 & 11,01 \\
\hline Jaú SP & 7.080 & 84 & $\begin{array}{r}84,2 \\
9 \\
\end{array}$ & Varginha MG & 15.655 & 3.677 & 4,26 & Jaboticabal SP & 14.613 & 2.135 & 6,84 \\
\hline Araraquara SP & 7.036 & 230 & $\begin{array}{r}30,5 \\
9 \\
\end{array}$ & Jaboticabal SP & 14.947 & 2.097 & 7,13 & Assis SP & 13.845 & 1.221 & 11,34 \\
\hline Rio de Janeiro RJ & 5.791 & 1.565 & 3,82 & Araraquara SP & 13.702 & 1.886 & 7,27 & Sudoeste de Goiás GO & 13.114 & 4.407 & 2,98 \\
\hline Assis SP & 5.528 & 93 & $\begin{array}{r}59,4 \\
4 \\
\end{array}$ & São João da Boa Vista SP & 12.267 & 2.440 & 5,03 & Varginha MG & 12.842 & 3.815 & 3,37 \\
\hline Bauru SP & 5.432 & 206 & $\begin{array}{r}26,3 \\
7 \\
\end{array}$ & $\begin{array}{l}\text { São Sebastião do Paraíso } \\
\text { MG }\end{array}$ & 11.735 & 1.991 & 5,89 & $\begin{array}{l}\text { São João da Boa Vista } \\
\text { SP }\end{array}$ & 12.678 & 2.559 & 4,95 \\
\hline Fortaleza CE & 5.225 & 260 & $\begin{array}{r}14,8 \\
8 \\
\end{array}$ & Ilhéus/Itabuna BA & 10.934 & 3.148 & 3,47 & Porto Seguro BA & 12.301 & 2.357 & 5,22 \\
\hline Uberlândia MG & 5.147 & 346 & $\begin{array}{r}20,1 \\
0 \\
\end{array}$ & Uberlândia MG & 10.015 & 2.91990 & 3,35 & Barreiras BA & 11.460 & 1.225 & 9,36 \\
\hline São Paulo SP & 4.206 & 1.248 & 3,37 & Jaú SP & 9.318 & 1.096 & 8,50 & Uberlândia MG & 11.183 & 3.468 & 3,22 \\
\hline Joaçaba SC & 3.810 & 144 & $\begin{array}{r}26,4 \\
6 \\
\end{array}$ & São José do Rio Preto SP & 9.178 & 3.048 & 3,01 & Bauru SP & 10.740 & 1.949 & 5,51 \\
\hline \multicolumn{12}{|c|}{ FEMININO } \\
\hline & 89 & & & & 99 & & & & 09 & & \\
\hline
\end{tabular}




\begin{tabular}{|c|c|c|c|c|c|c|c|c|c|c|c|}
\hline Microrregiões & $\begin{array}{c}\text { Emprego } \\
\text { s (A) }\end{array}$ & $\begin{array}{c}\text { Firmas } \\
\text { Rurais } \\
\text { (B) }\end{array}$ & $A / B$ & Microrregiões & $\begin{array}{l}\text { Empr } \\
\text { egos } \\
\text { (A) }\end{array}$ & $\begin{array}{c}\text { Firmas } \\
\text { Rurais } \\
\text { (B) }\end{array}$ & $A / B$ & Microrregiões & $\begin{array}{c}\text { Empr } \\
\text { egos } \\
\text { (A) }\end{array}$ & $\begin{array}{c}\text { Firmas } \\
\text { Rurais } \\
\text { (B) }\end{array}$ & A/B \\
\hline Ribeirão Preto SP & 2.525 & 175 & $\begin{array}{r}14,4 \\
3 \\
\end{array}$ & Araraquara SP & $\begin{array}{r}3.20 \\
9 \\
\end{array}$ & 1.886 & 1,70 & Araraquara SP & $\begin{array}{r}5.87 \\
0 \\
\end{array}$ & 1.418 & 4,14 \\
\hline Araraquara SP & 1.987 & 230 & 8,64 & Campinas SP & $\begin{array}{r}2.50 \\
7 \\
\end{array}$ & 1.285 & 1,95 & Jaboticabal SP & $\begin{array}{r}5.37 \\
5 \\
\end{array}$ & 2.135 & 2,52 \\
\hline São Paulo SP & 1.624 & 1.248 & 1,30 & Ribeirão Preto SP & $\begin{array}{r}2.39 \\
6\end{array}$ & 1.471 & 1,63 & Moji Mirin SP & $\begin{array}{r}3.50 \\
6\end{array}$ & 1.135 & 3,09 \\
\hline Campinas SP & 1.510 & 278 & 5,43 & Joaçaba SC & $\begin{array}{r}1.83 \\
3 \\
\end{array}$ & 733 & 2,50 & Joaçaba SC & $\begin{array}{r}3.31 \\
3 \\
\end{array}$ & 1.372 & 2,41 \\
\hline Jaú SP & 1.449 & 84 & $\begin{array}{r}17,2 \\
5 \\
\end{array}$ & Jaboticabal SP & $\begin{array}{r}1.79 \\
7 \\
\end{array}$ & 2.097 & 0,86 & Campinas SP & $\begin{array}{r}3.06 \\
4 \\
\end{array}$ & 1.469 & 2,09 \\
\hline Botucatu SP & 1.148 & 121 & 9,49 & Petrolina PE & $\begin{array}{r}1.78 \\
4 \\
\end{array}$ & 451 & 3,96 & Bauru SP & $\begin{array}{r}3.06 \\
3 \\
\end{array}$ & 1.949 & 1,57 \\
\hline Cornélio Procópio PR & 1.102 & 144 & 7,65 & Porto Alegre RS & $\begin{array}{r}1.72 \\
7 \\
\end{array}$ & 871 & 1,98 & Vacaria RS & $\begin{array}{r}3.03 \\
4 \\
\end{array}$ & 1.229 & 2,47 \\
\hline $\begin{array}{l}\text { Santo Antônio de Jesus } \\
\text { BA }\end{array}$ & 1.098 & 25 & $\begin{array}{r}43,9 \\
2\end{array}$ & Varginha MG & $\begin{array}{r}1.70 \\
9\end{array}$ & 3.677 & 0,46 & Sudoeste de Goiás GO & $\begin{array}{r}2.71 \\
9\end{array}$ & 4.407 & 0,62 \\
\hline Uberlândia MG & 1.057 & 346 & 3,05 & Belo Horizonte MG & $\begin{array}{r}1.63 \\
9\end{array}$ & 1.818 & $\begin{array}{r}0,199 \\
0\end{array}$ & $\begin{array}{l}\text { São João da Boa Vista } \\
\text { SP }\end{array}$ & $\begin{array}{r}2.69 \\
1\end{array}$ & 2.559 & 1,05 \\
\hline Maringá PR & 1.042 & 53 & $\begin{array}{r}19,6 \\
6 \\
\end{array}$ & $\begin{array}{l}\text { São João da Boa Vista } \\
\text { SP }\end{array}$ & $\begin{array}{r}1.62 \\
0 \\
\end{array}$ & 2.440 & 0,66 & Pirassununga SP & $\begin{array}{r}2.43 \\
0 \\
\end{array}$ & 693 & 3,51 \\
\hline
\end{tabular}

Fonte: Resultados da Pesquisa. 


\subsection{Distribuição Espacial do Emprego Formal na Agropecuária por Gênero}

No emprego masculino o maior número de empregos situa-se entre o Estado de São Paulo, limitando-se, por vezes aos estados de Minas Gerais, Goiás, Ceará, Bahia e Rio de Janeiro. Já para o emprego feminino, a concentração acontece não só nas regiões já citadas mas acentuadamente em São Paulo. Também se distribuem nos estados de Santa Catarina, Rio Grande do Sul e Paraná, indicando uma dispersão maior que o apresentado no emprego masculino.

Figura 3. Emprego Formal na Agropecuária por Gênero nas microrregiões Brasileiras em 1989, 1999 e 2009
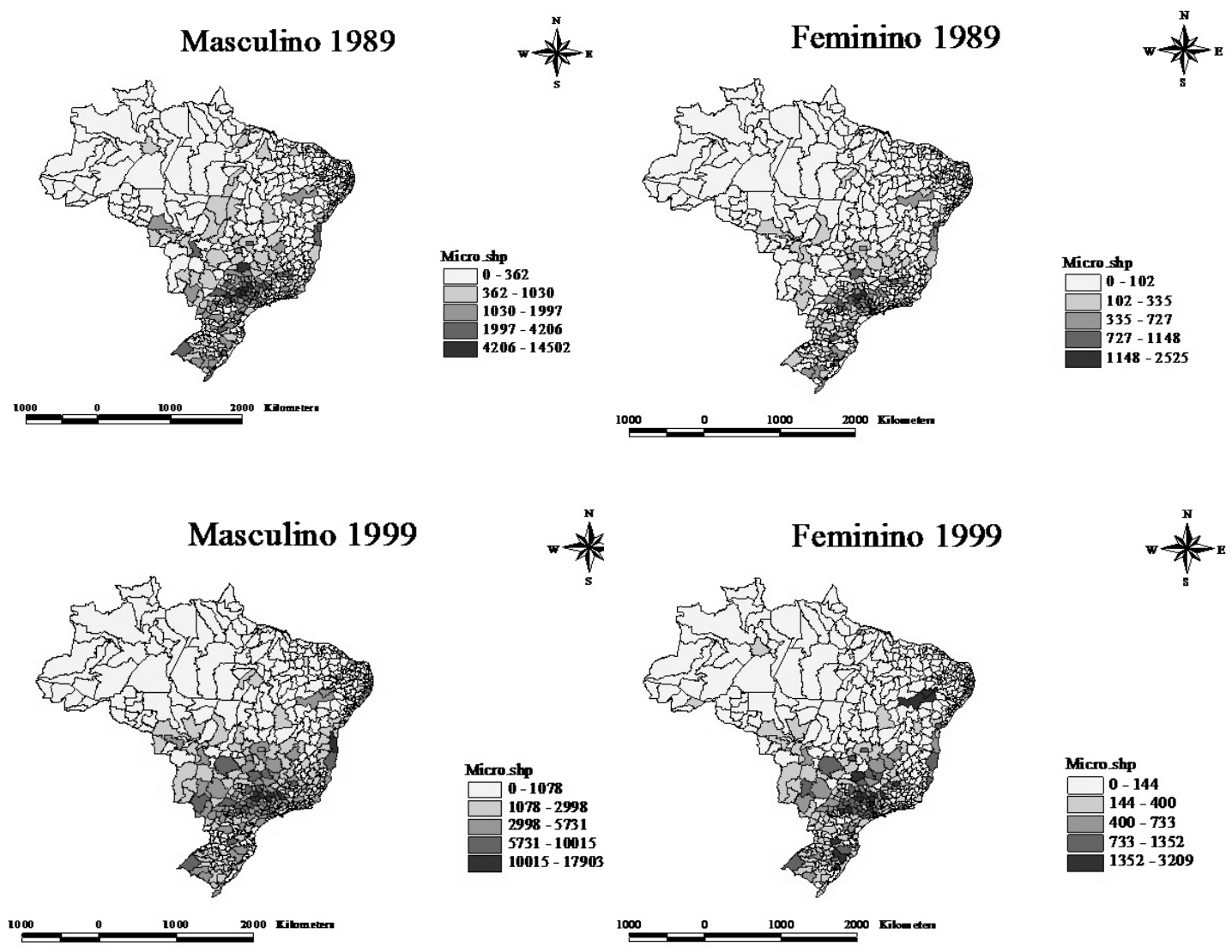

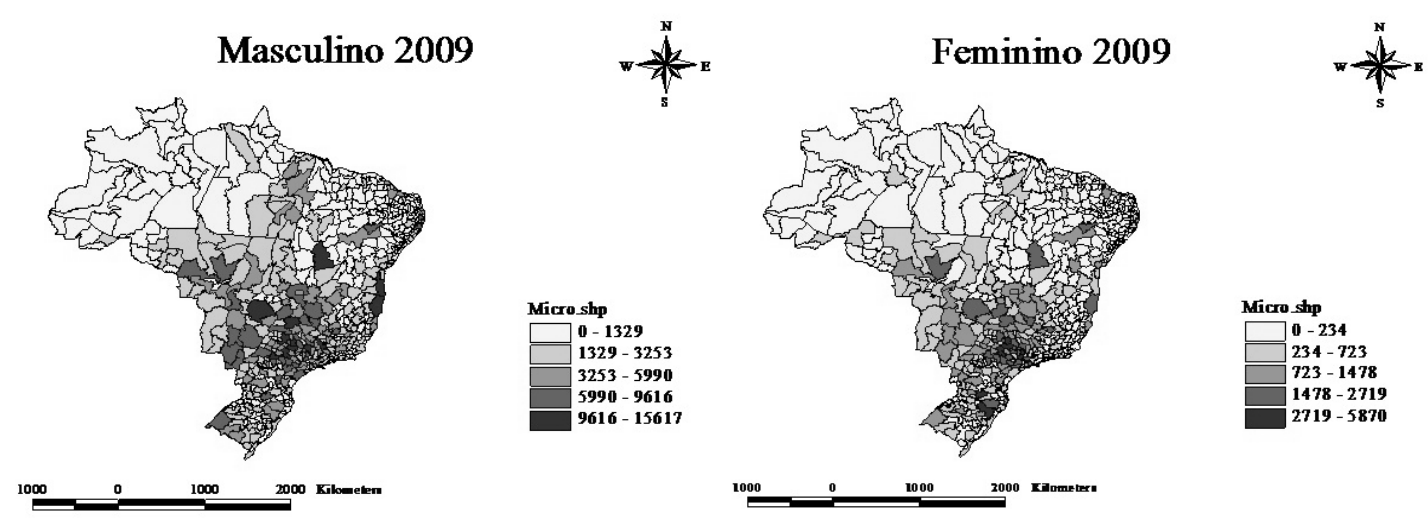

Fonte: Elaboração própria a partir dos dados da RAIS.

Há que se considerar que essa demanda é justificada pela mesma razão exposta para o emprego formal total, ou seja, o perfil da agropecuária paulista. Conforme mostrado por Vicente et al (2005), a modernização da agricultura, ao vir acompanhada da monocultura crescente, casos mais da cana-de-açúcar e da laranja, demandou intensamente a ocupação das trabalhadoras para sustentar sua expansão. Mas, como alertado por Petti \& Fredo (2009), e que não pode ser sonegado, esse crescimento acontece, porém, em percentual bem menor do que o aumento das áreas novas e da produção, mais aptas para a colheita mecanizada.

Para esses autores, a inserção dessa trabalhadora como boia fria reflete o próprio desenvolvimento da agricultura, com mudanças nos processos produtivos e nas formas de organização das atividades. Este é o caso, e já citado anteriormente, da contratação para o corte da cana que não revela preferência entre homens ou mulheres, o que importa às empresas sucroalcooleiras é a produtividade, ou seja, a quantidade de toneladas que o trabalhador possa cortar em dias normais. Embora o corte da cana apresente-se como uma atividade em que predomina a ocupação masculina, a presença da mulher ocorre dada a habilidade que possui no manuseio do podão.

No entanto, mesmo apresentando essa evolução significativa, a participação da mulher no universo do emprego formal agrícola ainda é tímida se comparada a do homem. Isso porque a sua inserção como mão de obra ainda é caracterizada como trabalho complementar ou o doméstico do meio rural. $\mathrm{O}$ outro indicador a ser apontado, mas não 
analisado neste trabalho, é a diferença salarial entre gêneros. Mesmo apresentando culturas, como a cana-de-açúcar, que não distingue sexo, a média salarial das mulheres para o setor agrícola ainda é 35\% inferior ao rendimento dos homens, segundo Georgino (2008). A autora justifica que, pelo fato de a mão de obra na maior parte ser familiar, elas acabam trabalhando na lavoura da família sem receber por isso.

Detalhando mais essa distribuição do emprego formal por gênero, a Figura 4 apresenta esta distribuição espacial nas microrregiões brasileiras. Um outlier ${ }^{4}$ significa que uma área não segue o mesmo processo de dependência espacial das demais.

4 Os outliers são observações discrepantes, tanto superiores como inferiores, dos dados referentes ao emprego formal agrícola por gênero bayesiano nas microrregiões brasileiras. 
Figura 4. Mapa do emprego formal na Agropecuária nas microrregiões por Outliers*
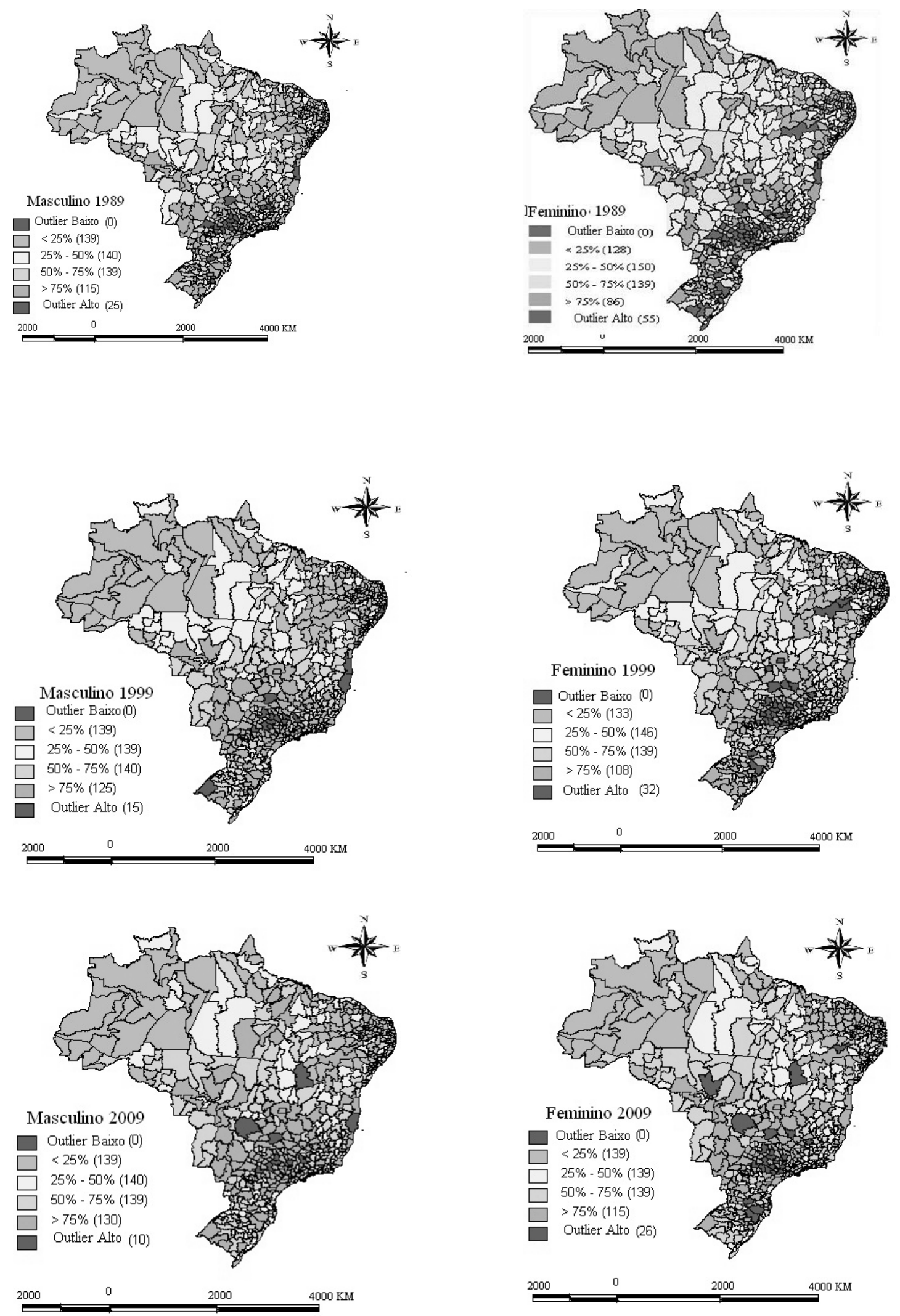

Fonte: Resultados da Pesquisa. 
* O critério de hedge adotado foi 3.

Por fim, para a confirmação dos dados, é necessário, junto à visualização do mapa, um acompanhamento com testes sobre a hipótese de aleatoriedade espacial. As informações sobre o grau de dependência espacial são obtidas pelo diagrama de dispersão de Moran.

Para verificar a presença de autocorrelação espacial do número de empregos formais da agricultura por gênero, o diagrama de dispersão de Moran (I de Moran) indica o grau de dependência espacial. Os valores acima do I de Moran calculado representam a existência da autocorrelação espacial positiva e os valores abaixo representam a autocorrelação espacial negativa.

Quando não existe um padrão espacial nos dados, o valor encontrado é o I de Moran esperado. Para as microrregiões brasileiras, o valor esperado para as 558 unidades espaciais do território analisado foi $E(I)=-0,0018$. Portanto, os valores acima de $E(I)=-0,0018$ indicam a autocorrelação espacial positiva e os valores inferiores indicam a autocorrelação espacial negativa. Na Tabela 2, encontram-se os valores de I de Moran, calculado para as variáveis descritas anteriormente.

Tabela 2. Coeficiente de I de Moran do Emprego formal na Agropecuária por gênero para os anos de 1989, 1999 e 2009

\begin{tabular}{lll}
\hline Variaveis & 1 & Probabilidade \\
\hline MASC89 & 0,3224 & 0,01 \\
FEM89 & 0,3213 & 0,01 \\
MASC99 & 0,4912 & 0,01 \\
FEM99 & 0,3996 & 0,01 \\
MASC09 & 0,4371 & 0,01 \\
FEM09 & 0,4618 & 0,01 \\
\hline
\end{tabular}

Fonte: Resultados da pesquisa.

Nota: a pseudo-significância empírica é baseada em 999 permutações aleatórias. $E(\Lambda)=-0,0018$.

De acordo com esta tabela, a autocorrelação espacial positiva do número de empregos formais da agropecuária por gênero foi significativa a $1 \%$ de significância. Nesse caso, isso mostra que existe uma relação entre a variável do número de empregos formais por 
gênero feminino e masculino e a localização espacial da variável, ou seja, microrregiões que possuem alto número de empregos formais da agropecuária por gênero estão rodeadas por microrregiões que possuem alto número de empregos formais da agropecuária por gênero. Nesse mesmo raciocínio, microrregiões que possuem baixo número de empregos formais da agropecuária por gênero estão rodeadas por microrregiões que possuem baixos números de empregos formais da agricultura por gênero.

Já a Tabela 3 apresenta o I de Moran bivariado, ou seja, o índice comparado entre duas variáveis do modelo. O número de emprego formal por gênero feminino e masculino é comparado com a média do rendimento em salário mínimo por gênero. Como pode ser verificado, existe autocorrelação espacial positiva entre as variáveis significando que microrregião com alto número de emprego formal por gênero masculino e feminino está associado a microrregiões com alta média do rendimento em salário mínimo por gênero masculino e feminino.

Tabela 3. Coeficiente de I de Moran Global bivariado entre Emprego formal na Agropecuária por gênero pela Média do Rendimento em Salários Mínimos do Gênero na Agropecuária

\begin{tabular}{llll}
\hline Variáveis & $\mathrm{l}$ & p-valor & Sig. \\
\hline MASC89 \& RENM89 & 0,1778 & 0,0010 & $1 \%$ \\
FEM89 \& RENF89 & 0,0604 & 0,0010 & $1 \%$ \\
MASC99 \& RENM99 & 0,0780 & 0,0010 & $1 \%$ \\
FEM99 \& RENF99 & 0,0400 & 0,1040 & $\mathrm{NS}$ \\
MASC09\& RENM09 & 0,2716 & 0,0010 & $1 \%$ \\
FEM09\& RENF09 & 0,0901 & 0,0010 & $1 \%$ \\
\hline
\end{tabular}

Fonte: Resultados da Pesquisa.

Para Almeida (2004), o I de Moran Global bivariado encontra o valor de uma variável observada, em uma determinada área, em relação com os valores da variável observada nas áreas vizinhas. Ou seja, o índice gerado é resultado da comparação entre duas variáveis. A variável dependente (número de emprego formal por gênero feminino e masculino) é comparada com a média do rendimento em salário mínimo por gênero masculino e feminino. 
Os maiores níveis de autocorrelação espacial são entre o número de emprego formal por gênero masculino e a média do rendimento em salário mínimo por gênero masculino $(0,2716)$ no ano de 2009 e em 1989 (0,1778), com o nível de pseudo-significância de autocorrelação positiva de $1 \%$. Apenas para a autocorrelação entre número de emprego formal por gênero feminino e a média do rendimento em salário mínimo por gênero feminino no ano de 1999, foi positivo, porém, com o nível de pseudo-significância não significativo. Os demais coeficientes de I de Moran foram significativos e positivos.

Os padrões globais detectam a autocorrelação espacial para todo o espaço analisado. O problema do I de Moran Global é que ele pode esconder padrões locais ou ser influenciado por eles. Para superar esses problemas estatísticos torna-se imprescindível verificar a formação de clusters e/ou agrupamentos (KLEINSCHMIT, 2009).

A Figura 5 apresenta os mapas com formação de clusters e está divido em quatro categorias de associação espacial. A figura também demonstra que os clusters formados são estatisticamente significantes para o I de Moran Local e o número de empregos formais na agropecuária por gênero (masculino e feminino). 
Figura 5. Mapa de cluster Univariado do emprego formal na Agropecuária por gênero para os anos de 1989, 1999 e 2009

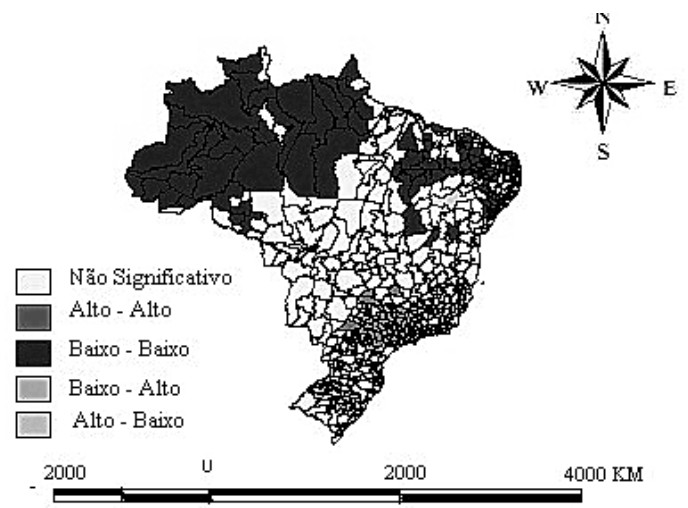

Masculino 89

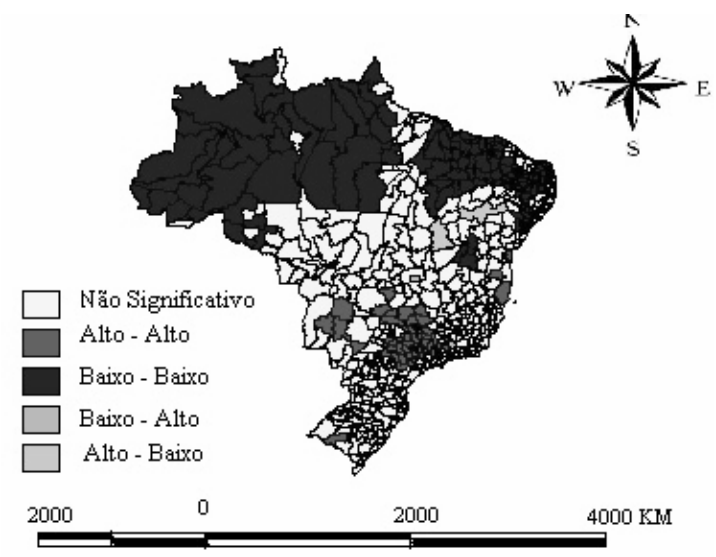

Masculino 99

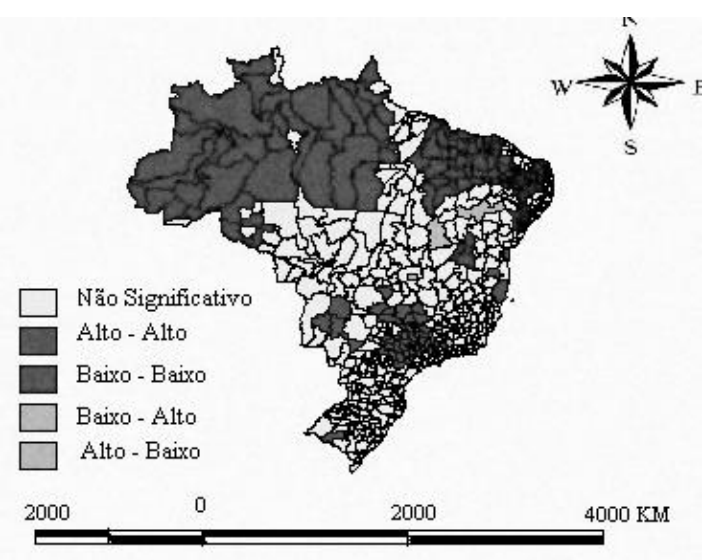

Masculino 09

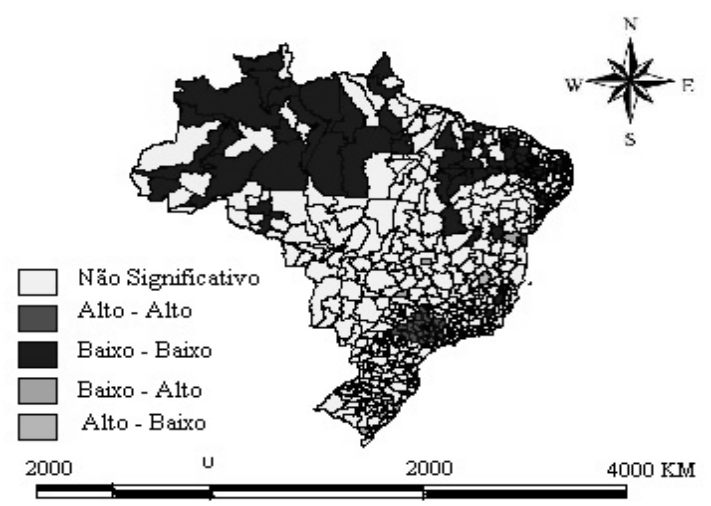

Feminino 89

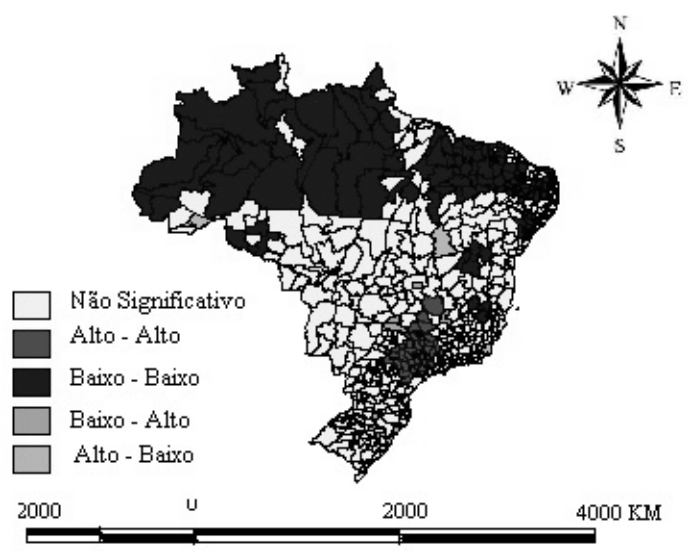

Feminino 99

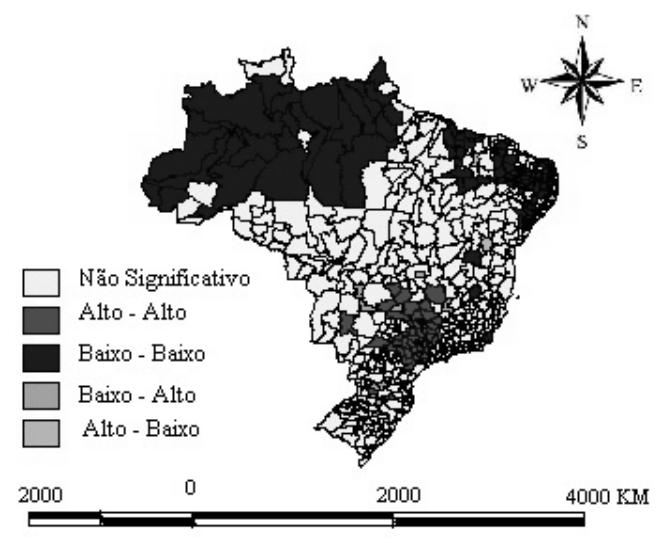

Feminino 09

Fonte: Resultados da Pesquisa. 
Conforme Almeida (2004), o coeficiente de autocorrelação espacial local apresenta o grau de associação linear (positiva ou negativa) entre o valor de uma variável em uma determinada região e a média de outra variável nas locações vizinhas.

Na visualização do mapa de clusters da figura 4, percebe-se que, tanto o gênero masculino quanto o feminino, tiveram um aumento em extensão no cluster tipo alto-alto (microrregiões com numero elevado de emprego formal na agropecuária por gênero, circunvizinhos de microrregiões com números altos de emprego formal na agropecuária) entre 1989, 1999 e 2009. No caso masculino a concentração se faz entre o Estado de São Paulo, alongando-se em direção a Região CentroOeste. Já no gênero feminino, vai em direção a Minas Gerais e Goiás, sendo que, em 2009, houve um cluster em Mato Grosso do Sul e Santa Catarina.

O cluster baixo-baixo, formado por microrregiões com número baixo de emprego formal na agropecuária por gênero circunvizinhos de microrregiões com número baixo de emprego formal agropecuária, é formado por microrregiões da Região Norte e Nordeste do Brasil e entre os anos de 1989 e 2009, tanto para o sexo masculino como para o feminino, houve aumento em sua extensão ao longo destas regiões geográficas.

\section{CONSIDERAÇÕES FINAIS}

Considerando os objetivos propostos pelo trabalho de analisar a distribuição espacial do emprego formal na agropecuária total e por gênero nas microrregiões brasileiras nos anos de 1989, 1999 e 2009, verificou-se a existência de clusters, e examinou-se o nível de correlação entre as variáveis emprego formal e rendimento. Constatouse, mediante a AEDE, uma maior concentração de contratações formais nas microrregiões do Estado de São Paulo para os três períodos analisados. Essas regiões se caracterizam pela composição de produção agropecuária que possui produtos intensivos em mão de obra, como cana de açúcar, café e laranja.

A despeito das informações sobre o grau de dependência espacial, as estimativas do / de Moran global evidenciaram a autocorrelação 
espacial positiva entre as microrregiões brasileiras tanto para o emprego formal total quanto por gênero. Isto significa que as regiões com elevada (baixa) contratação são rodeadas por regiões com elevada (baixa) valor da mesma variável.

Quando se especificou a análise da distribuição do emprego formal por gênero para os três períodos - levando-se em consideração a presença de microrregiões tidas como outliers, ou seja, uma área não segue o mesmo processo de dependência espacial das demais -, verificou-se que, dentre as 558 microrregiões brasileiras analisadas nos anos de 1989, 1999 e 2009, nenhuma possuía outliers baixos. Os anos analisados apresentaram tanto para o contingente feminino quanto masculino a existência de outliers altos, em outras palavras, que exercem influência espúria sobre a média global de autocorrelação.

Já o I de Moran bivariado, ou seja, o índice comparado entre duas variáveis do modelo, no caso, o número de emprego formal por gênero feminino e masculino comparada com a média do rendimento em salário mínimo por gênero, verificou-se que os maiores níveis de autocorrelação espacial são entre o número de emprego formal por gênero masculino e a média do rendimento em salário mínimo por gênero masculino para o ano de 2009. Apenas para a autocorrelação entre número de emprego formal por gênero feminino e a média do rendimento em salário mínimo por gênero feminino no ano de 1999, foi positivo, porém, com o nível de pseudo-significância não significativo. Os demais coeficientes de I de Moran foram significativos e positivos.

Analisando os clusters, percebe-se que, tanto o sexo masculino quanto o feminino, tiveram um aumento em extensão no cluster tipo alto-alto (microrregiões com número elevado de emprego formal na agropecuária por gênero, circunvizinhos de microrregiões com números altos de emprego deste setor) entre 1989, 1999 e 2009. No caso masculino a concentração se faz entre o estado de São Paulo alongando-se em direção à Região Centro-Oeste. Já no gênero feminino, vai em direção a Minas Gerais e Goiás, sendo que, em 2009, houve um cluster em Mato Grosso do Sul e Santa Catarina.

O cluster baixo-baixo é formado por microrregiões da Região Norte e Nordeste do Brasil e, entre os anos de 1989 e 2009, tanto para o sexo masculino como para o feminino, houve aumento em sua extensão ao longo destas regiões geográficas. 
Por fim, cabe ressaltar que é evidente a maior concentração do número de contratações formais no Estado de São Paulo, tanto no número total quanto por gênero. Como exposto anteriormente, essa demanda é justificada pelo perfil da agropecuária paulista. Ao longo do período analisado, houve um aumento da demanda por mão de obra em virtude da expansão da agricultura e de sua modernização. Porém, é importante considerar que esta expansão aconteceu em percentual bem menor do que o aumento das áreas novas e da produção, mais aptas para a colheita mecanizada.

Quanto à contratação feminina, nestes 20 anos, houve um aumento do número de mulheres assalariadas com carteira assinada não só no Estado de São Paulo, como também em regiões que antes não apresentavam números significativos de contratações, como Joaçaba (SC), Vacaria (RS) e sudoeste de Goiás (GO). No entanto, esses números ainda estão bem abaixo das contratações masculinas, isto porque a sua inserção como mão de obra ainda é caracterizada como trabalho complementar ou o doméstico do meio rural.

\section{REFERÊNCIAS}

ALMEIDA, Eduardo Simões de. Curso de econometria espacial aplicada. Piracicaba: ESALQ-USP, 2004.

BALSADI, Otavio Valentim. Características do emprego rural no Estado de São Paulo nos anos 1990. 2000. 160f. Dissertação (Programa de PósGraduação em Desenvolvimento Econômico - Mestrado e Doutorado) Universidade Estadual de Campinas, Campinas, 2000.

BALSADI, Otavio Valentim. Panorama dos salários na agricultura brasileira em 2005. Analises e Indicadores do Agronegocio. São Paulo, v.2, n.9, p. 1 - 5, set. 2007.

BRUSCHINI, M.C.A. Trabalho e Gênero no Brasil nos últimos dez anos. Cadernos de Pesquisa, v. 37, n. 132, p.537-572, set./dez. 2007.

CASARI, Priscila. Segmentação no mercado de trabalho brasileiro:

diferenças entre o setor agropecuário e os setores não agropecuários, 
período de 2004 a 2009. 2012. 139f. Tese de doutorado (Escola Superior de Agricultura Luiz de Queiroz) - Universidade de São Paulo, Piracicaba, 2012.

CUNHA, M. S. Os empregados da Agricultura Brasileira: diferenciais e determinantes salariais. Revista de Economia e Sociologia Rural, Piracicaba, v.46, n.3, p. 597 - 621, jul. /set.2008.

DEL GROSSI, M. E; GRAZIANO DA SILVA, J. As mudanças no rural brasileiro no início do milênio. In: SEMINÁRIO DE ANÁLISE DOS RESULTADOS DA PNAD 2004, 2006, Brasília. Anais... Brasília: Centro de Gestão e Estudos Estratégicos, 2006.

FREITAS, C.; BACHA, C. J. C. Contribuição do capital humano para o crescimento da pecuária brasileira - período de 1970 a 1996. Revista Brasileira de Economia, v.58 (4), p.533-557, Rio de Janeiro, 2004.

GEORGINO, M. Desmistificando a mão de obra feminina. Hortifruti Brasil, Piracicaba, v. 6, n. 65, p. 6-13, jan./fev. 2008.

GASQUES, J. G.; CONCEIÇÃO, J. C. P. R. Crescimento e produtividade da agricultura brasileira. Brasília: IPEA, 1997. 21 p. (Texto para Discussão, 502).

GRAZIANO DA SILVA, J. A nova dinâmica da agricultura brasileira. Campinas: Universidade Estadual de Campinas, Edições Campinas, 1996.

HOFFMANN, R. Desigualdade e polarização entre empregados na agricultura brasileira: 1992-2007. Economia e Sociedade, Campinas, v. 18 , n. 2 (36), p. 417-428, ago. 2009.

INSTITUTO BRASILEIRO DE GEOGRAFIA E ESTATISTA. Downloads. Disponível em: ftp://geoftp.ibge.gov.br/ . Acesso em 20 set. 2010.

KAGEYAMA, A. Mudanças no trabalho rural no Brasil, 1992-2002. Agricultura em São Paulo. São Paulo: V. 51, No. 2 p. 71-84, 2004. 
KLEINSCHMITT, Sandra Cristiana. Analise Espacial dos Homicidios nos Municípios do Estado do Paraná. 2009. 129f. Dissertação. (Mestrado em Desenvolvimento Regional e Agronegócio) - Universidade Estadual do Oeste do Paraná, 2009.

LEONE, E.T; MAIA A. G; BALTAR, P. A. Formalização do emprego no Brasil rural. XLV Congresso da Sober. 2007.

PEROBELLI, F. S. ; ALMEIDA, E. S. ; ALVIM, M. I. da S. A. ; FERREIRA, P. G . Análise espacial da produtividade do setor agrícola brasileiro: 19912003. In: XLIII Congresso da SOBER, 2005, Riberão Preto. Anais do XLIII Congresso da SOBER, 2005

PETTI R; FREDO C. E; Emprego Formal na Cana de açúcar. Análises e Indicadores do Agronegócio. Instituto de Economia Agrícola. V.4 n. 4 abril 2009

PINHEIRO, Maria Andrade. Distribuição espacial da agropecuária do Estado do Paraná: um estudo da função de produção. 2007. $126 \mathrm{f}$. Dissertação (Mestrado em Ciências Econômicas) - Universidade Estadual de Maringá, Maringá, 2007.

IBGE. Pesquisa Nacional por Amostra de Domicilio. Instituto Brasileiro de Geografia e Estística. Microdados. 2005.

RELAÇÃO ANUAL DE INFORMAÇÕES SOCIAIS (RAIS). 2010. Disponível em: <www.sjp.pr.gov.br>. Acesso em: 27/09/2010.

ROCHA, C. B.; PARRÉ, J. L. Estudo da Distribuição Espacial do Setor Agropecuário o Rio Grande do Sul. Análise Econômica, Porto Alegre, ano 27, n. 52, p. 139-160, set. 2009.

SCHNEIDER, S. Agricultura familiar e emprego no meio rural brasileiro: análise comparativa das Regiões Sul e Nordeste. Parcerias estratégicas, Brasília - DF, v. 1, p. 217-244, 2006. 
STADUTO, J. A. R.; SHIKIDA, P. F. A.; BACHA, C. J. C. Alteração na composição da mão de obra assalariado na agropecuária brasileira. Agricultura em São Paulo, São Paulo, v. 51, n. 2, p. 57-70, 2004.

STADUTO, J. A. R.; ROCHA JR, W.; BITENCOURT, M. B. Contratos no mercado de trabalho agrícola: o caso das cooperativas de trabalhadores rurais. Revista de Economia e Sociologia Rural, Rio de Janeiro, v. 42, n. 4, p. 619-643, 2004.

VICENTE, M.C.M.; NOGUEIRA, E.A.; BAPTISTELLA, C.S.L. Estimativas de mão de obra e demografia no setor agrícola paulista: 1986/97. Informações Econômicas, São Paulo, v.18, n.8, p.29-37, ago. 1998.

VICENTE, M.C.M.; BAPTISTELLA, C.S.L; FRANCISCO, V.L.S. Evolução do mercado de trabalho na agropecuária paulista, 1995 - 2004. In: XLIII Congresso da SOBER, 2005, Ribeirão Preto. Anais do XLIII Congresso da SOBER, 2005. 
Submetido em 29/05/2013.

Aprovado em 09/06/2015.

\section{Sobre os autores}

Patrícia Estanislau

Economista. Mestre em Desenvolvimento Regional e Agronegócio da Universidade Estadual do Oeste do Paraná - Campus de Toledo - PR.

Professora da UNESPAR - Universidade Estadual do Paraná campus de Campo Mourão PR.

Endereço: Av. Comendador Norberto Marcondes $n^{\circ} .733$ - CEP 87.303-100 - Campo Mourão - PR - Brasil.

E-mail: patiestanislau@yahoo.com.br.

\section{Paula Tissiany Carneiro}

Economista. Mestre em Teoria Econômica pela Universidade Estadual de Maringá, Maringá- PR. Professora da UNESPAR -Universidade Estadual do Paraná campus de Apucarana - PR.

Endereço: Av. Minas Gerais nº 5021 - CXP: 98 - CEP: 86800-970 - Apucarana - PR Brasil.

E-mail: paula_eco@yahoo.com.br.

\section{Kézia Bondezan}

Economista. Doutora em Teoria Econômica pela Universidade Estadual de Maringá, Maringá- PR. Professora da UNESPAR -Universidade Estadual do Paraná campus de Apucarana - PR.

FECEA - Faculdade Estadual de Ciências Econômicas de ApucaranaAv. Minas Gerais $\mathrm{n}^{\circ}$. 5021 - CXP: 98 - CEP: 86800-970 - Apucarana - PR - Brasil.

E- mail: kezialucas@hotmail.com.

\section{José Luiz Parré}

Professor Associado da Universidade Estadual de Maringá. Pesquisador do CNPq. UEM - Universidade Estadual de Maringá, departamento de Ciências Econômicas Av. Colombo, 5790 - Bloco: C34 - sala 5 - Maringá - PR - Brasil.

E-mail: jlparre@uem.br 